> surprises in this programme," Howard told journalists at the briefing.

The report found that the JWST budget presented to NASA in 2008 "was not based upon a current, bottom-up estimate of projected costs" and therefore understated the project's real requirements. The agency also had inadequate monetary reserves each year to cover expenses that arose when costs turned out to be higher than estimated. NASA dealt with the problem by continually postponing necessary work so that it would fall under a subsequent year's budget, with the delay causing the work to double or triple in price.

The report admonishes NASA managers, saying that they were aware of the practice of deferring work into future years and "tacitly condoned it". For some, the findings are evidence that the agency has not got to grips with its tendency to allow programmes to overrun their budgets, which inevitably means that money is siphoned from other projects. "We seem to be better at observing lessons, rather than learning from them," says Matt Mountain, director of the Space Telescope Science Institute in Baltimore, Maryland.

The JWST will need about \$250 million per year of extra funds in 2011 and 2012, and such estimates represent the minimum, says Casani. Given that the newly elected Congress wants to reduce spending, the extra funds might be unavailable and the launch date would have to be postponed, driving up costs still further, he adds.

The grim outlook limits NASA's ability to carry out recommendations from the Astro2010 decadal survey, a community-wide effort to assign priorities to major projects, says Alan Stern, a planetary scientist at the Southwest Research Institute in San Antonio, Texas.

"It seems that there was no need for NASA to participate in the decadal, as there are unlikely to be any funds available before 2020 to start anything big and new," says Alan Boss, chair of the NASA advisory council astrophysics subcommittee and an astrophysicist at the Carnegie Institution for Science in Washington DC. Particularly vulnerable, says Stern, is the Wide-Field Infrared Survey Telescope (WFIRST), the decadal survey's top large-scale, space-based project. The mission, intended to study the 'dark energy' driving the acceleration of the Universe's expansion, is estimated to cost $\$ 1.6$ billion.

Despite its dysfunctional financing, the JWST is technically sound and should still proceed, the report finds, a view widely shared in the community. Mountain points out that it required nearly $\$ 6$ billion in today's dollars to get the Hubble telescope working as it was intended, and few would argue that the money wasn't well spent.

"It's good to do one hard project a decade; it reminds us what revolutionary things look like," he says. @ SEE EDITORIAL P.346

\title{
Good news for 'good' cholesterol
}

\section{Positive results inject life into strategy to treat heart disease.}

\section{BY ALLA KATSNELSON}

A strategy for lowering heart-disease risk that once seemed to be a dead end is showing fresh promise. Decades of animal studies and epidemiological data had suggested that raising blood levels of high-density lipoprotein - HDL, or 'good' cholesterol - might have a stronger protective effect against heart disease than statins, drugs that lower levels of low-density lipoprotein ('bad' cholesterol or LDL). But in 2006, a US\$1-billion trial of torcetrapib, an HDL-raising drug, found it seemed to increase patients' risk of death, casting a pall of doubt over the entire field. This week, the first study since to focus on the class of drugs that boosts HDL levels may offer good news for the approach.

The study, published in The New England Journal of Medicine ${ }^{1}$, was a 1,623-patient trial investigating the safety of anacetrapib, a drug functionally similar to torcetrapib, developed by pharmaceutials giant Merck, based in Whitehouse Station, New Jersey. The drug inhibits a protein called CETP, which raises HDL. The trial found with $94 \%$ confidence that anacetrapib does not harm patients - in contrast to the 15,000-patient trial of torcetrapib, also a CETP inhibitor. When Pfizer halted that trial early ${ }^{2}$, many companies stopped working on CETP blockers. Researchers were left wondering whether torcetrapib's failure was down to unexpectedly high toxicity in that compound, whether the inhibition of CETP itself is harmful, or whether the idea that raising HDL levels lowers risk is flawed.

The anacetrapib trial also tracked the drug's effects on LDL and HDL levels, which, according to Christopher Cannon, a cardiovascular researcher at Brigham and Women's Hospital in Boston, Massachusetts, and the study's principal investigator, are "jawdropping". After 24 weeks on the drug, patients experienced a $138 \%$ increase in HDL levels. In contrast, exercising and changing diet might only raise HDL by $10 \%$, says Cannon. The participants, all of whom were also on statins, experienced a further $40 \%$ reduction in LDL levels.

Although the study wasn't large enough to look at the effect of anacetrapib on heart disease, the researchers noted some positive trends: $3.3 \%$ of patients taking the drug experienced heart attacks, stroke or other kinds of cardiovascular events, compared with $5.3 \%$ of patients in the placebo group.

The drug's apparent safety is encouraging, says Prediman Shah, director of cardiology and atherosclerosis research at Cedars-Sinai Medical Center in Los Angeles, California, "but there are some interesting red flags". One, he says, has to do with c-reactive protein (CRP), a marker of inflammation in blood that tends to drop as patients regulate their cholesterol with statins or lifestyle changes. Despite the huge changes in LDL and HDL levels, CRP levels actually increased slightly.

Shah also says he is surprised that such enormous shifts in HDL levels yielded such small clinical benefits. "In all fairness, the study wasn't powered to test that," says Shah, but if epidemiological predictions on HDL's benefits are correct, the drug should virtually "confer immortality".

Whether raising HDL really works won't become clear until data from larger studies begin to emerge, Shah says. An international, 30,000-patient trial testing anacetrapib's efficacy will begin next year, but results won't come in until at least 2014 (see Table). Meanwhile, results on another CETP inhibitor called dalcetrapib, developed by Roche, are expected in 2013.
1. Cannon, C. P. et al. N. Engl. J. Med. doi:10.1056/ NEJMoa1009744 (2010).
2. Pearson, H. Nature 444, 794-795 (2006).

\section{TESTING THE EFFICACY OF RAISING LEVELS OF HIGH-DENSITY LIPOPROTEIN}

\begin{tabular}{l|l|l|l|}
\hline Drug/class & Company & Clinical phase & Results expected \\
\hline $\begin{array}{l}\text { Anacetrapib (CETP inhibitor) } \\
\text { Dalcetrapib (CETP inhibitor) }\end{array}$ & Merck & Enrolling phase III early 2011 & $2014-15$ \\
\hline $\begin{array}{l}\text { Niacin + MK-0524A (to control } \\
\text { niacin's side effects) }\end{array}$ & Merck & Phase III & 2013 \\
$\begin{array}{l}\text { RVX-208 (stimulates production } \\
\text { of apoA-1, a key HDL protein) }\end{array}$ & Resverlogix & Phase IIb & 2012 \\
\hline
\end{tabular}

